\title{
Experimental Investigation of PCBN Cutting Tool Insert When Hard Turning Hardened 42CrMo4 Steel
}

\author{
Musonda Emmanuel Kabaso ${ }^{1}$, Chen Yongjie ${ }^{2}$ \\ ${ }^{I}$ School of Mechanical Science and Engineering, Huazhong University of Science and Technology, 1037 Luo Yu \\ Road, Wuhan, Hubei 430074, P. R. China; \\ ${ }^{2}$ School of Mechanical Science and Engineering, Huazhong University of Science and Technology, 1037 Luo Yu \\ Road, Wuhan, Hubei 430074, P. R. China;
}

\begin{abstract}
The goal of this experimental analysis was to observe the behavior of a polycrystalline cubic boron nitride(PCBN) tool during hard turning of chromium-molybdenum alloy hardened steel $\left(42 \mathrm{CrMo}_{4}\right)$.Individual cutting parameter influences on the general tool wear patterns were quantitatively evaluated on the basis of appropriate physical and mathematical modeling approaches. The outcomes indicated that PCBN tool suggests good wear resistance regardless of the aggressiveness of the $42 \mathrm{CrMo}_{4}$ at $62 \mathrm{HRC}$. At $200 \mathrm{~m} / \mathrm{min}$, the machining system became uneven and resulted in significant sparks and vibrations just after a few minutes. At higher speeds roughness $\left(R_{a}\right)$ was stabilized due to a reduction in the cutting forces. Surface quality attained with PCBN tool considerably compares with that of grinding. Even when the tool wear $V B$ reached $0.3 \mathrm{~mm}$, the majority of the recorded $R_{a}$ values did not exceed $1 \mu \mathrm{m}$ at the various speeds tested. The correlation of tool wear $V B$ and surface roughness $R_{a}$ established allows obtaining experimental empirical data on the cutting tool wear from measured surface roughness for practical use in industry.
\end{abstract}

Keywords: -Hard Turning, Tool Life, Tool Wear, Surface Roughness, Chromium-Molybdenum Alloy Steel, Polycrystalline Cubic Boron Nitride.

\section{INTRODUCTION}

Better usage of polycrystalline cubic boron nitride (PCBN) turning tools can effectively be realized with a detailed understanding of PCBN tool wear patterns and models. This is because in each different hard machining operation, wear patterns are believed to be varied in each of the individual cutting parameter contributions. In addition, despite the obvious benefits of hard turning, further application of hard turning has been hindered mainly due to limited understanding of tool wear and tool failure. Likewise, experimental evidence for hard turning to gain industrial application for a specific hard turning application in most cases is inevitable. Furthermore, lack of suitable cutting conditions in the use of PCBN tools currently present a huge gap for the process to be effectively used in industry. Moreover, in order to minimize or eradicate the possibility of scrapping an expensive part, the most appropriate cutting conditions before a part is put into production must be determined.

Currently hard turning application is further enhanced by the use of new materials such as Polycrystalline cubic boron nitride (PCBN) for making cutting tools [1]. However, the machining of these materials is becoming difficult due to the quality and precision requirements in most industries. Nevertheless, many difficult-to-machine, highly abrasive materials are becoming ideal for the application of PCBN tools. This is because these tools are able to achieve high quality and economic efficiency comparable to that of grinding. The possibility of high speed, long tool life, highest surface quality, optimal process reliability and 
repeatability has made PCBN cutting tools gain even more importance in the mechanical manufacture of new and harder materials. In addition, dry cutting presents ecological benefits for manufacturing enterprises by reducing overhead costs and protecting the environment because of the possibility of excluding cutting coolants [2]. Moreover, studies byTonshoffet. al [3] observed that despite the small depths of cut and feed rates essential for hard turning, material removal rates in hard turning can be much greater than grinding for some applications. Studies show that accurate components can be manufactured by hard turning without secondary processes such as grinding and lapping. Engineers continue to desire materials that are capable of longer service lives, and processes for shaping those materials into finished products that are capable of maintaining tighter and consistence geometric tolerances and improved surface finish [4]. In order to remain competitive in today's market, companies should enhance high product quality and reduce costs while fulfilling strict customer requirements [5]. As a result, more and deep tool wear investigations are continuously required particularly in the machining of harder steels using high performance tool materials such as PCBN.Therefore, this study hoped to add empirical experimental data in this field to advance the use of PCBN cutting tools in industry.

It is worth noting that the applications of stainless steel materials have immensely increased in various engineering fields. The combination of good corrosion resistance, high wear resistance, wide range of strength levels, high surface finish, good formability and aesthetically pleasing appearance have made stainless steels as a good choice for a wide range of applications. But, their machinability is more difficult compared to other alloy steels due to low thermal conductivity, high built-up edge (BUE) formation tendency and high deformation when hardened.

The research linked to wear of cutting tools in hard turning has been focused on two major aspects. One aspect has been to find out the capability of certain cutting tools to undergo hard turning processes within a reasonable tool life. The other aspect has been to examine tool wear evolution and the behavior of the cutting conditions such that tool life is increased. The deductions of wear studies so far are sometimes contradictory and insufficient. However, a strong influence of cutting speed and the workpiece material has been reported by most authors. For these reasons, additional research must be done to determine how cutting parameters affect both tool wear and surface integrity.

From the reviewed literature it is evident that the tool wear mechanism is a complex phenomenon involving different types of wear which in turn have an effect on the tool life of the cutting tool. In addition surface roughness measurement is vital to control quality of machined components. Because of this many authors have considered surface roughness as the fourth element of the design [6]. Therefore, to appreciate how tool wear influences the tool life and surface roughnessvarious models have been developed to explain these relationships[7].

\section{TOOL WEAR AND TOOL LIFE}

Tool wear occurs at the contact zone between the cutting tool, workpiece and chips generated [8].Many authors advocate that, the failure of the cutting tool is as a result of premature failure of the tool (i.e., tool breakage) and progressive wear of the tool. Generally, the wear of the cutting tool depends on the tool material and tool geometry, workpiece materials, cutting parameters (feed rate, cutting speed and depth of cut etc.), coolants and machine characteristics[9].Therefore, in order to avoid economic loses, information about the state of tool wear is essential to plan tool changes. Cutting tool wear leads to product rejects, machine down time and can also be a source to personnel problems. In turning, tool wear becomes an additional parameter affecting surface quality of finished parts. In addition, increasing tool wear produces unsatisfactory surface finish and high power consumption.

Meanwhile, Tool life in many studies has been found to be very sensitive to feed rate and cutting speed. 
The tool flank wear is one of the commonly used wear parameter to determine tool life in cutting processes because it is easy to measure and can be represented by the Taylor tool-life equation for the linear portion of the curves developed as shown in equation (1):

$$
V_{c} \times T_{c}^{l / k}=C
$$

The Taylor tool- life equation enables the evaluation of tool life data and can be used to predict tool life as well as dispersion and confidence intervals within the equation [10].

\section{EXPERIMENTAL PROCEDURE AND PLAN}

\subsection{Cutting Tool Material}

PCBN is a material which is sintered at extremely high pressure and high temperature into a wear-resistant material and does not have a tendency to react with ferrous materials [11,12, 13].The material is suited for finishing of super heat resistant alloys [14].In this study, a PCBN cutting insert of the standard designation CNGA120408S01030AWH was proposed to perform moderate range hard turning operations on 42CrMo4 steel (HRC 62).

\subsection{Workpiece Material}

The selected work piece material for investigation was chromium-molybdenum alloy steel $\left(42 \mathrm{CrMo}_{4}\right) \mathrm{HRC}$ 62 with the compositions as depicted in Table 1. The material's mechanical properties are outlined in Table 2. The length and diameter of the parts used in the tests were $450 \mathrm{~mm}$ and $148 \mathrm{~mm}$, respectively.

Table 1: ChemicalComposition of Chromium-Molybdenum Alloy Steel (42CrMo $)$

\begin{tabular}{cccccccc}
\hline $\mathrm{C}$ & $\mathrm{Cr}$ & $\mathrm{Mn}$ & $\mathrm{Mo}$ & $\mathrm{P}$ & $\mathrm{Si}$ & $\mathrm{S}$ & $\mathrm{Fe}$ \\
0.405 & 0.95 & 0.875 & 0.2 & $\leq 0.035$ & 0.225 & $\leq 0.040$ & 97.278 Bal. \\
\hline
\end{tabular}

Table2: Mechanical Properties of Chromium-Molybdenum Alloy Steel 42CrMo )

\begin{tabular}{cccccc}
\hline $\begin{array}{c}\text { Hardness, } \\
\text { Brinell BHN }\end{array}$ & $\begin{array}{c}\text { Hardness, } \\
\text { Rockwell HRB }\end{array}$ & $\begin{array}{c}\text { Tensile } \\
\text { Strength, } \\
\text { Ultimate }\end{array}$ & $\begin{array}{c}\text { Tensile Strength, } \\
\text { Yield }\end{array}$ & $\begin{array}{c}\text { Elongation } \\
\text { (in 50 mm) }\end{array}$ & $\begin{array}{c}\text { Reduction of } \\
\text { Area }\end{array}$ \\
\hline $197(105)$ & 62 & $655 \mathrm{MPa}$ & $415 \mathrm{MPa}$ & $25.7 \%$ & $56.9 \%$ \\
\hline
\end{tabular}

\subsection{Experimental Plan}

To understand both the wear behavior and life, long term experimental tests according to ISO 3685 standard were performed to make use of the well-known Taylor life model [15].Tool wear was examined under the following hard turning cutting parameters: cutting speed $\left(V_{c}\right)$ ranging from 105 to $200 \mathrm{~m} / \mathrm{min}$, feed rate $\left(f_{n}\right)$ of 0.15 $\mathrm{mm} / \mathrm{rev}$ and cutting depth $\left(a_{p}\right)$ of $0.5 \mathrm{~mm}$. A permissible flank wear value $[V B]$ of $0.3 \mathrm{~mm}$ was adopted for the PCBN tool life. However, wear values were acquired beyond this limit to observe the inclusive PCBN tool wear behavior, under severe conditions.

The Semi-Automatic DMTG - CW6163E horizontal turning lathe with a variable spindle speed between 7.5 and $1000 \mathrm{rpm}$ and a power rating of $11 \mathrm{~kW}$ was used to conduct the turning experiments. A PCBN cutting insert was mounted on a PCLNR2525M12 turning Tool-Holder $95^{\circ}$ right hand cutting $25 \times 25 \mathrm{~mm}$ of $32 \mathrm{~mm}$ shank width and $150 \mathrm{~mm}$ long. The surface roughness was measured using a Mitutoyo 178-561-02A Surftest SJ-210 surface roughness tester. Cutting force was measured by interfacing Kistler dynamometer (9129AA) and charge amplifier (5070A) with a data acquisition system type 5697A (DAQ) in three components according to the directions $\mathrm{X}, \mathrm{Y}$ and $\mathrm{Z}$. Machining was also stopped when the notch wear depth was more than 
$1.00 \mathrm{~mm}$ and when the tool was severely broken (catastrophic failure). For purposes of achieving finish machining results applicable in industry, an additional tool life criterion was set such that the machined surface roughness was no more than $1.6 \mu \mathrm{m}$. The tool wear was observed using Wanhao image measuring instrument VMS-1510G.The layout of the equipment for force measurement and tool wear measurement is depicted in Fig.1.

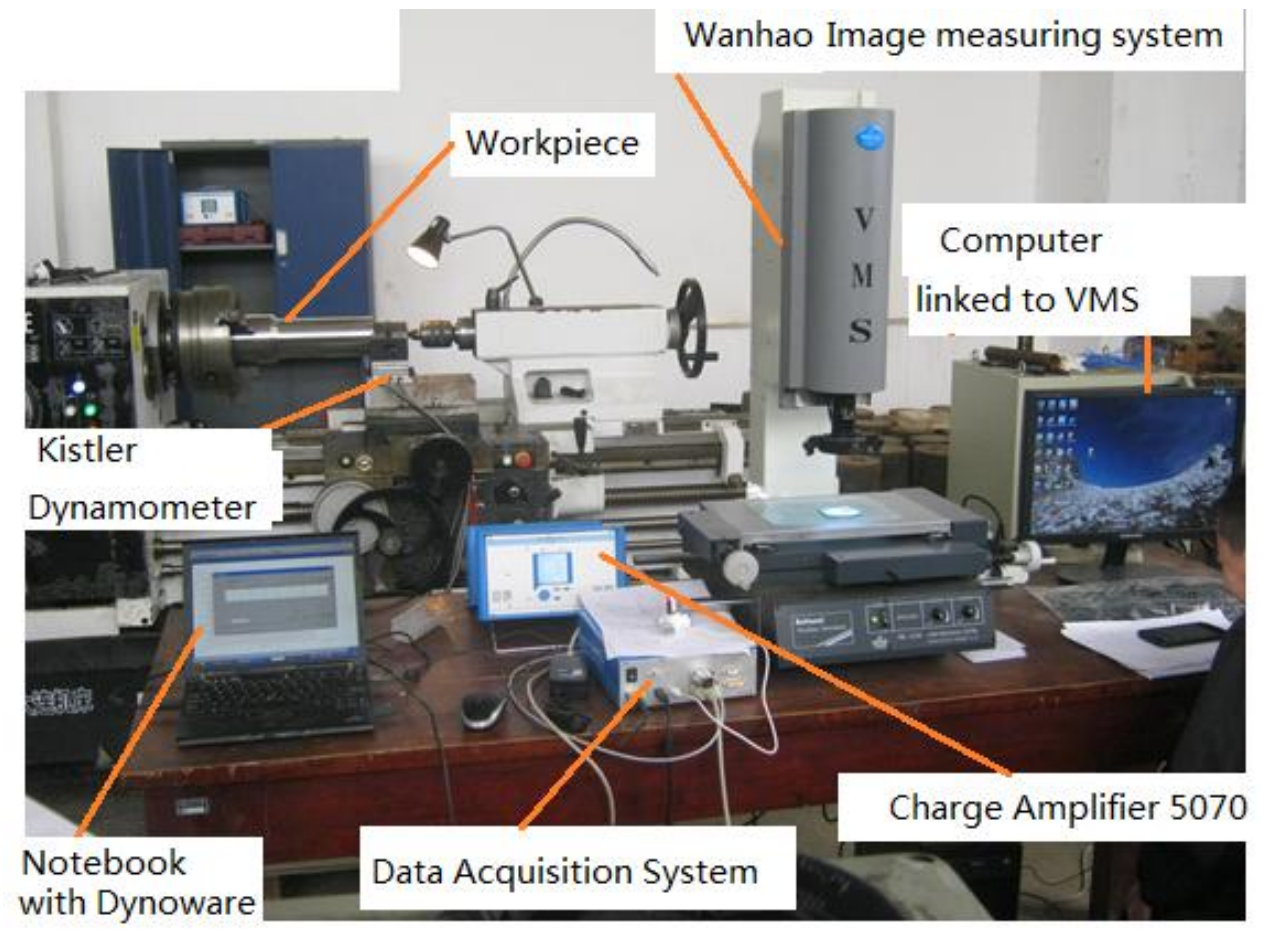

Fig.1: Layout of the Equipment for Force Measurement and Tool Wear Measurement

\section{RESULTS AND DISCUSSIONS OF TOOL-LIFE DATA EVALUATION}

\subsection{Tool life Evaluation}

Table 3 shows the tool life values obtained at different combinations of cutting speed and feed rate in this research.

Table 1: Tool Life at Various Cutting Speeds and Feed Rate [ $V B<0.3 ; R a<1.6$; No breakage]

\begin{tabular}{cccc} 
Exp.No. & $\begin{array}{c}\text { Cutting speed } \\
(\mathbf{m} / \mathbf{m i n})\end{array}$ & Feed(mm/rev) & $\begin{array}{c}\text { Tool life } \\
(\mathbf{m i n})\end{array}$ \\
1 & 105 & 0.15 & 203 \\
2 & 105 & 0.2 & 223 \\
3 & 105 & 0.3 & 44 \\
4 & 140 & 0.15 & 102 \\
5 & 140 & 0.2 & 60 \\
6 & 140 & 0.3 & 3 \\
7 & 170 & 0.15 & 68 \\
8 & 170 & 0.2 & 35 \\
9 & 170 & 0.3 & 2 \\
10 & 200 & 0.15 & 48 \\
11 & 200 & 0.2 & 6 \\
12 & 200 & 0.3 & 0.5 \\
\hline
\end{tabular}

The method of least squares was used to fit the line which entailed that the sum of the squares of the deviations between the observation points and the line was minimized. The procedure and calculation are presented in Table 
4 and 5.

Table 4: Computation Schedule for Calculation of Regression Line $y=a+k(x-\bar{x})$

\begin{tabular}{|c|c|c|c|c|c|c|c|}
\hline 1 & 2 & 3 & 4 & 5 & 6 & 7 & 8 \\
\hline $\begin{array}{l}\text { Obsn. } \\
\text { No. }\end{array}$ & $\begin{array}{c}V c \\
\mathrm{~m} / \mathrm{min}\end{array}$ & $\begin{array}{l}\text { Tc, } \\
\min \end{array}$ & $x=\log V c$ & $y=\log T c$ & $x y$ & $x^{2}$ & $y^{2}$ \\
\hline 1 & 105 & 203 & 2.021 & 2.307 & 4.664 & 4.085 & 5.325 \\
\hline 2 & 105 & 223 & 2.021 & 2.348 & 4.746 & 4.085 & 5.515 \\
\hline 3 & 105 & 44 & 2.021 & 1.643 & 3.322 & 4.085 & 2.701 \\
\hline 4 & 140 & 102 & 2.146 & 2.009 & 4.311 & 4.606 & 4.034 \\
\hline 5 & 140 & 60 & 2.146 & 1.778 & 3.816 & 4.606 & 3.162 \\
\hline 6 & 140 & 3 & 2.146 & 0.477 & 1.024 & 4.606 & 0.228 \\
\hline 7 & 170 & 68 & 2.230 & 1.833 & 4.087 & 4.975 & 3.358 \\
\hline 8 & 170 & 35 & 2.230 & 1.544 & 3.444 & 4.975 & 2.384 \\
\hline 9 & 170 & 2 & 2.230 & 0.301 & 0.671 & 4.975 & 0.091 \\
\hline 10 & 200 & 48 & 2.301 & 1.681 & 3.869 & 5.295 & 2.827 \\
\hline 11 & 200 & 6 & 2.301 & 0.778 & 1.791 & 5.295 & 0.606 \\
\hline 12 & 200 & 0.5 & 2.301 & -0.301 & -0.693 & 5.295 & 0.091 \\
\hline \multirow[t]{5}{*}{ Sum } & & & $\sum x=26.096$ & $\begin{array}{l}\sum y=16.3 \\
99\end{array}$ & $\sum x y=35.052$ & $\sum x^{2}=56.882$ & $\sum y^{2}$ \\
\hline & & & $\left(\sum x\right)^{2}$ & $\sum x \sum y$ & & & \\
\hline & & & $=681.022$ & $=427.957$ & & & \\
\hline & & & $\left(\sum x\right)^{2} / n=$ & $\sum x \sum y / n$ & & & \\
\hline & & & 56.752 & $=35.663$ & & & \\
\hline
\end{tabular}

Criterion $[V B]=0.3 \mathrm{~mm}$; Number of observation $=12$

Table 5: Computed Values for $k, a$ and $C$

$$
\begin{array}{cc}
\bar{x}=\frac{\sum x}{n}=2.175 & k=-4.688 \\
a=k(\bar{x}-\log C)=\bar{y}=\frac{\sum y}{n}=1.367 & -1 / k=0.213 \\
k=\frac{\sum x y-\left[\left(\sum x \sum y\right) / n\right]}{\sum x^{2}-\left(\sum x\right)^{2} / n}=-4.688 & \log C=\bar{x}-\bar{y} / k=2.466 \\
C=292.536\{\mathrm{~m} / \mathrm{min}\}
\end{array}
$$

The calculated constants $k$ and $C$ in the Taylor tool-life equation for the observations were -4.688 and 292,536 $\mathrm{m} / \mathrm{min}$ respectively. The parameter $C$ is the cutting speed corresponding to a one-minute tool life on the $\log -\log$ plot of the tool life data. Equation (1) of the Taylor tool life equation for the investigated data was therefore;

$292.536=V_{C} T_{C}^{-1 /-4.688}$ or $292.536=V_{C} T_{C}^{0.213}$ or $T_{c}=e^{7.181} V^{-4.688}$

The residual sum of squares computed by the least square technique is used as the algebraic criterion to denote the 
best fit. Dispersion is at the center of all experimental observations and one way of representing the dispersion is by computation of residual deviation about the regression line. The $95 \%$ confidence level was selected and from Fischer's $F$-table, the $F$-value for the number of degrees of freedom (d.f.) equal to 1 and $n-2$ was 4.96 . Table 6shows the calculations of the variance ratio and how to compare it with the $F$ value.

Table 6: Calculation of Variance Ratio and Comparison with $F$-value

\begin{tabular}{lccc}
\hline Source of variation & Degrees of freedom (d.f.) & Mean-square sum & $\boldsymbol{F}$-Ratio \\
Regression & 1 & $s_{R}^{2}=2.865$ & $\frac{s_{R}^{2}}{S_{r}^{2}}=5.681$ \\
& $\mathrm{n}-2=10$ & $s_{r}^{2}=0.504$ & \\
Residuals & & \\
\hline
\end{tabular}

Confidence level: 95\%; Read $F$-value from Fisher's $F$-table for d.f. $=1, \mathrm{n}-2=; F=4.96$

The computed $s_{R}^{2} / S_{r}^{2}$ ratio (5.681) was greater than the $F$-value (4.96) in the $F$-table showing that the observed relationship should not to be considered as a of result chance.

Confidence interval limits for the complete line were computed by using quantities obtained from Table 4 and 5. The 95\% level of confidence was chosen and the two-sided $t$-value read from the Student's $t$-table for the number of degrees of freedom equal to $n-2$ was 2.228. The calculated maximum and minimum constants for $k$ were -9.075 and -0.302 respectively. While the maximum and minimum values for the constant $C$ were 188.327 and 347.536 respectively establishing the range for the tool cutting parameters.

\subsection{Effect of Cutting Speed on Tool Wear}

Outcomes on PCBN tool wear progression (flank) as a function of cutting timeare depicted in Fig.2.

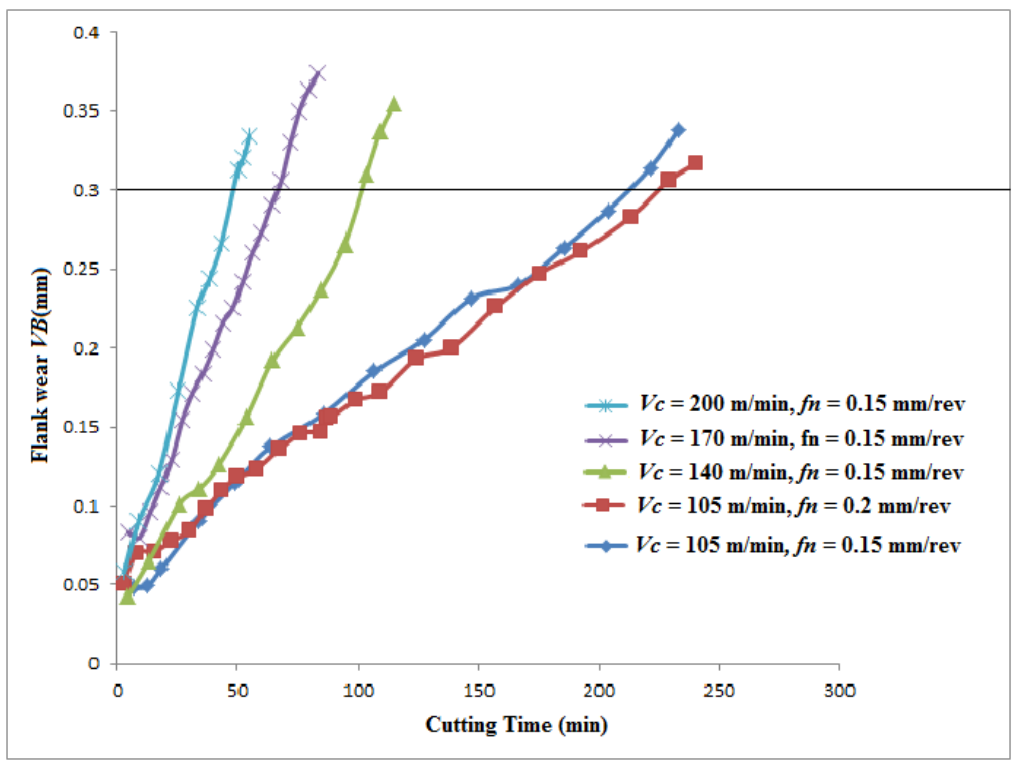

Fig.2:Progression of Flank Wear $(V B)$ as a Function of Cutting Time (Minutes)

As observed from the Fig.2 the tool flank wear development was in accordance with the universal wear law of any mechanical workpiece (initial rapid wear, normal wear, accelerated wear). Nonetheless, the increase in cutting speed had a great influence on the tool wear behavior as swift rise of the wear commenced from the cutting speed of $140 \mathrm{~m} / \mathrm{min}$. As a result the extent of the normal wear zone is significantly reduced as confirmed when testing at 105,170 and $200 \mathrm{~m} / \mathrm{min}$. At $105 \mathrm{~m} / \mathrm{min}$, the normal wear zone extends to $170 \mathrm{~min}$, at $170 \mathrm{~m} / \mathrm{min}$; it needs about $50 \mathrm{~min}$, while at $200 \mathrm{~m} / \mathrm{min}$ the normal wear zone is only $30 \mathrm{~min}$. The Flank wear trend is relatively 
stronger than crater wear trend the reason why $V B$ wear was used as the principal criterion of tool life $[16,17,18]$

\subsection{Microscopic Interpretations of Wear Morphology}

Microscopic observations as a function of time at various cutting speeds are of practical use to interpreting the $V B$ wear morphology. Cutting speeds of $105 \mathrm{~m} / \mathrm{min}$ and $140 \mathrm{~m} / \mathrm{min}$ presented no difficulty in machining. The tool wear on the flank surface was even. Initially, it was manifested by the appearance of a grooved and shining band especially near the end on the wear zone. As the machining time increased, the flank wear value $(V B)$ increased generating discontinuous chips. The machining system was relatively stable within these cutting speeds. The crater wear developed as a small cup on the rake surface in the first minutes of machining and spread with time (Fig.3(a). As the cutting speed increased to $140 \mathrm{~m} / \mathrm{min}$, mechanical and thermal activities on the cutting edge increased permitting small grooves to be formed after $26 \mathrm{~min}$ on the flank surface along the cutting speed direction with a notable notch wear. The flank wear enlarged in width and increased to become uneven after 65 minutes of machining. Machining becomes difficult showing fairly dark burnt colored continuous chips on the 84th minute of cutting. Fragments on the tool rake surface due to the high stresses produced from the cutting process were perceived. The quick evolution of $V B$ led to a large notch wear of the PCBN tool nose (Fig.3(b).

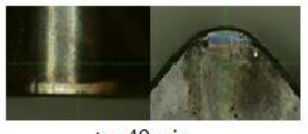

$\mathrm{t}=49 \min$

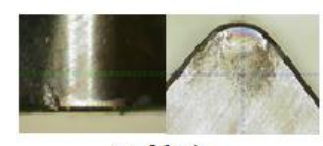

$\mathrm{t}=26 \min$

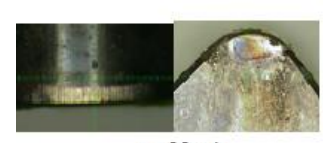

$\mathrm{t}=23 \min$

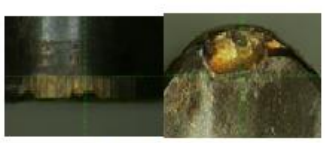

$\mathrm{t}=25 \min$

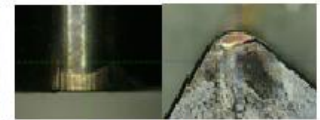

$\mathrm{t}=127 \mathrm{~min}$

(a)

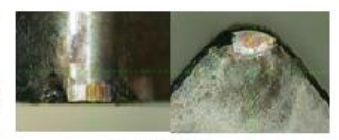

$\mathrm{t}=94 \mathrm{~min}$

(b)
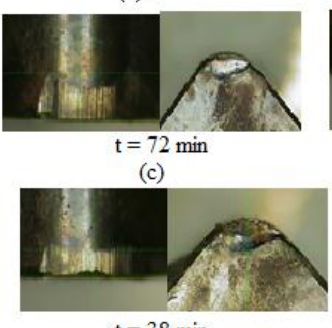

(d)

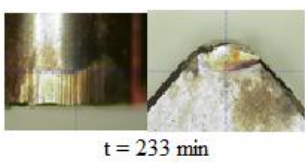

$\mathrm{t}=233 \min$

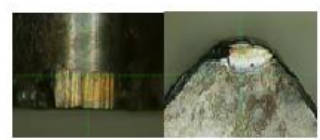

$\mathrm{t}=115 \min$
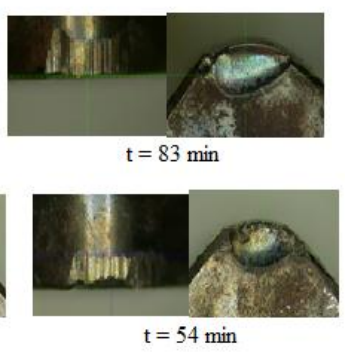

Fig.3: Micrographs of Flank and Crater Wear at Various Cutting Speeds $f_{n}=0.15 \mathrm{~mm} / \mathrm{rev}$ and $a_{p}=0.5 \mathrm{~mm}$ :

(a) $V_{c}=105 \mathrm{~m} / \mathrm{min}$; (b) $V_{c}=140 \mathrm{~m} / \mathrm{min}$; (c) $V_{c}=170 \mathrm{~m} / \mathrm{min}$; (d) $V_{c}=200 \mathrm{~m} / \mathrm{min}$

The beginning of the machining at $170 \mathrm{~m} / \mathrm{min}$ the system was stable with no chipping on the flank surface and the crater of the PCBN insert up to about 11 minutes. An even band of flank wear appears after $5 \mathrm{~min}$. (Fig.3(c). The $V B$ value increases in width and the crater becomes wider at the 23rd minute with a noticeable notch wear. At the end of $68 \mathrm{~min}$ of machining, wear $V B$ becomes irregular permitting small collapse on the PCBN tool nose and the notch wear was about 435 micrometers. Within $8 \mathrm{~min}$ of machining at $200 \mathrm{~m} / \mathrm{min}$, the insert chamfer undergoes quicker wear caused by temperature increase, and substantial chipping was seen on the rake surface. After $20 \mathrm{~min}$, the flank face became irregular and a small collapse of the tool nose was observed. Machining lasted with chipping on the rake surface that spread along the diagonal direction of the insert.

It was further observed that for all cutting speeds considered in this work grooves on tool flank surface appeared as the cutting progressed. These grooves were oriented along the cutting speed direction most likely resulting from high abrasive wear due the hard material being machined (Fig.3 (d). The latter seems to be the results of high abrasive wear. Once grooves initially appear at the beginning of the machining they never 
disappear (Fig.4), in agreement with what has been stated in literature [19]. The source of these grooves has been attributed to the tool binder damaged by the hard carbide particles of the workpiece leading to the fall out of PCBN tool grains. However profound analysis of the worn out surfaces indicate that the wear phenomenon as a result to diffusion due to high cutting speeds takes part in wear process of the rake surface of PCBN tool [16, 20, 21]. These two wear mechanisms (abrasion and diffusion) when combined generate accelerated tool surface wear and degradation of the cutting edge by a chipping process. As already noted the wear of cutting tool accelerates as the cutting progresses weakening the tool further and reduces the tool life of the cutting tool. This situation prompted me to examine the effect of tool wear on tool life if the cutting tool is to withstand the aggressive wear from the cutting process.

\subsection{Effect of Wear on Tool Life}

Detailed analysis of the flank wear (VB) in (Fig.2) against cutting time in the considered cutting speeds allows computation of different tool lives for the PCBN tool. For the analysis the cutting speed $\left(V_{c}\right)$ ranged from 105 to $200 \mathrm{~m} / \mathrm{min}$, the feed rate $\left(f_{n}\right)$ of $0.15 \mathrm{~mm} / \mathrm{rev}$ and cutting depth $\left(a_{p}\right)$ of $0.5 \mathrm{~mm}$. The tool life $(T)$ in minutes was found for the flank wear because it was much higher than the crater wear specifically at higher speeds. The analysis was done on the allowable $V B=0.3 \mathrm{~mm}$ wear criteria as summarized in Fig.4.

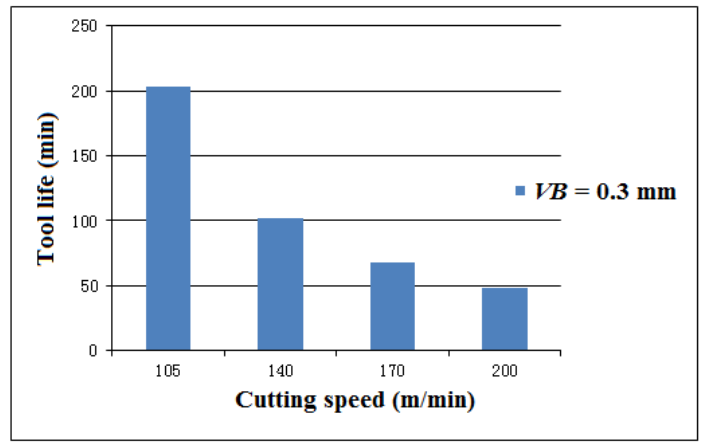

Fig. 4: Tool Life of PCBN at Various Cutting Speeds $\left(f_{n}=0.15 \mathrm{~mm} / \mathrm{rev}, a_{p}=0.5 \mathrm{~mm}\right)$

The tool life falls by $50 \%$ at cutting speeds of 105 to $140 \mathrm{~m} / \mathrm{min}$ with the speed ratio of 1.33 . For the increased speed range from 140 to $170 \mathrm{~m} / \mathrm{min}$ with speed ratio of 1.21 the observed tool life fall was $33 \%$. The tool life reduction for the next ranges of 170 to $200 \mathrm{~m} / \mathrm{min}$ was $29 \%$. It was clear that tool lifetime was sensitive to cutting speed variation. This could be due the presence of high temperatures produced around the tool nose by the cutting process supporting several wear mechanisms (abrasion and diffusion) and subsequently decreasing the cutting tool capacity.

The mechanical and thermal effect on the cutting edge is more evident at high cutting speeds. As a result the chip - tool interface and tool - workpiece experience frictions and high pressures that generate wear [22]

To show the influence of feed rate on tool life, cutting was done at 0.2 and $0.3 \mathrm{~mm} / \mathrm{rev}$ feed rate as indicated in Fig.5. 


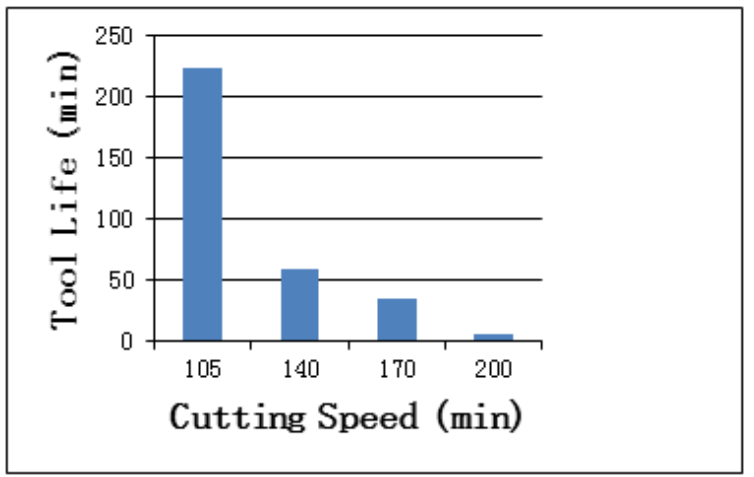

(a)

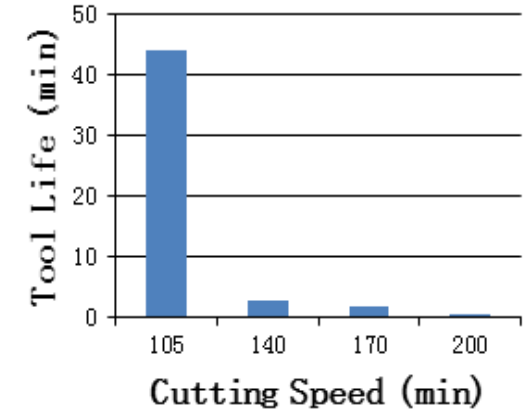

(b)

Fig.5: Tool Life of PCBN at Various Cutting Speeds $\left.(\mathrm{a}) f_{n}=0.2 \mathrm{~mm} / \mathrm{rev}, a_{p}=0.5 \mathrm{~mm}\right) ;(\mathrm{b})\left(f_{n}=0.3 \mathrm{~mm} / \mathrm{rev}\right.$,

$$
\left.a_{p}=0.5 \mathrm{~mm}\right)
$$

When feed rate was increased the tool life quickly reduced indicating that the feed rate had a strong influence on the tool life. When feed rate was increased to $0.3 \mathrm{~mm} / \mathrm{rev}$ the tool life at higher speeds was extremely short for industrial consideration. Noteworthy also was that the cutting forces increased gradually with the increase of the cutting distance and the tool flank wear. However, the machined workpiece surface roughness showed no significant change with the progress of the tool flank wear [23].

\subsection{Effect of Wear on Roughness}

Outcomes of Flank wear $V B$ on surface roughness are depicted in Fig.6 and Fig.7, for cutting speeds of 105 and $170 \mathrm{~m} / \mathrm{min}$.

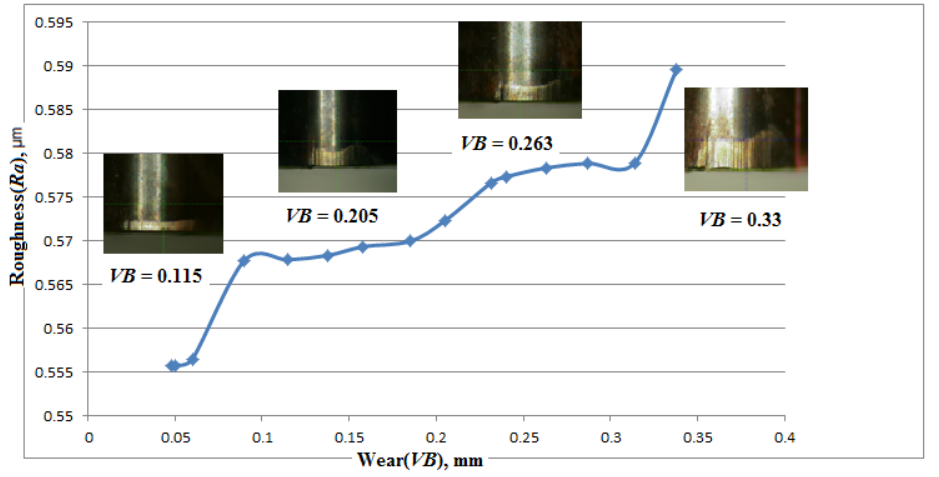

Fig.6: Influence of Wear on Roughness at $V_{c}=105 \mathrm{~m} / \mathrm{min} ; f_{n}=0.15 \mathrm{~m} / \mathrm{rev} ; a_{p}=0.5 \mathrm{~mm}$

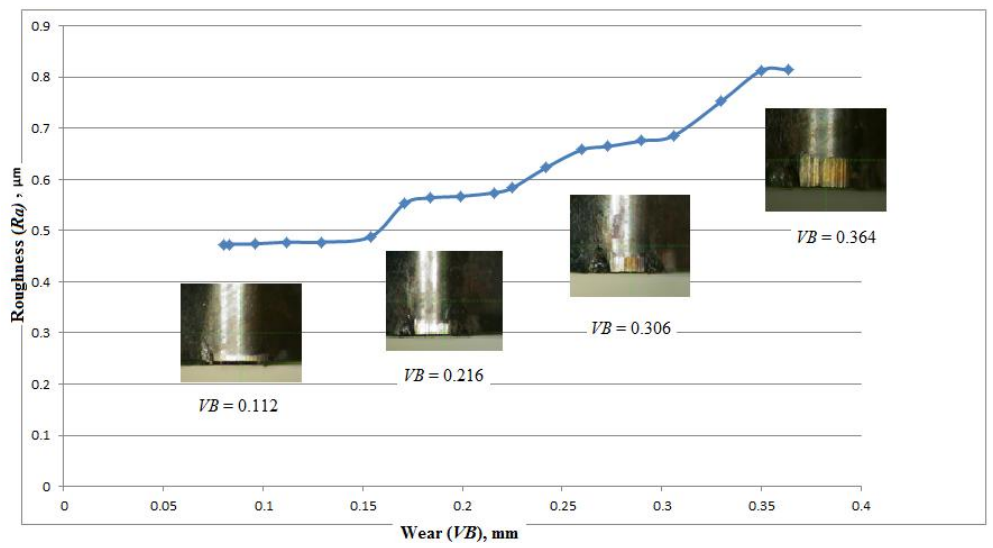

Fig.7: Influence of Wear on Roughness at $V_{c}=170 \mathrm{~m} / \mathrm{min} ; f_{n}=0.15 \mathrm{~m} / \mathrm{rev} ; a_{p}=0.5 \mathrm{~mm}$ 
During the cutting process there was no significant stable or uniform roughness value for surface roughness $\left(R_{a}\right)$, but sudden roughness increments as a function of machining time were noted. The uneven surface attained on the faces and cutting edges of the active tool part led to the degradation of roughness of the machined material. However, during a large portion of the machining time the curves indicated that PCBN ensured decent surface roughness quality. At $105 \mathrm{~m} / \mathrm{min}$ even after 200 minutes of cutting the surface roughness $R_{a}$ did not go beyond $1 \mu \mathrm{m}$. In fact for all the higher speeds of 140,170 and $200 \mathrm{~m} / \mathrm{min}$ the roughness $R_{a}$ remained lower than $1 \mu \mathrm{m}$ within the flank wear of 0 to $0.3 \mathrm{~mm}$. Microscopic observations of the tool nose. Fig. 7 explains the change in the surface roughness behavior as the function of $V B$ wear. The increasing wear micrographics describe the evolution from low roughness value when $V B=0.115 \mathrm{~mm}$ to a higher value $V B=0.33 \mathrm{~mm}$ and the region with higher roughness value for the cutting speed of $170 \mathrm{~m} / \mathrm{min}$ was $V B=0.362 \mathrm{~mm}$. At $105 \mathrm{~m} / \mathrm{min}$ for about 35 minutes a considerable constant surface roughness of $R_{a}=0.205$ is maintained. After 100 minutes the cutting generates an increased width of wear with small grooves on the flank face (abrasion wear). The thermo mechanical activities increased on the cutting edge producing several forms of the PCBN tool wear resulting in a surface roughness value of $0.262 \mu \mathrm{m}$. The $R_{a}$ was 0.579 after 200 minutes when the $V B$ was $0.33 \mathrm{~mm}$. Towards the end of machining after 203 minute the tool did not undergo significant wear degradation when $V B=0.338 \mathrm{~mm}$ and the machined surface quality $R_{a}=0.590$ remained under $1 \mu \mathrm{m}$. The surface roughness at $V_{c}=170 \mathrm{~m} / \mathrm{min}$ with the $V B$ wear increase from 0.112 to 0.306 showed minimal variations with values under 0.8 . The $R_{a}$ values above 0.8 towards the end of machining could be attributed to the large width of flank wear and significant notch wear. Nevertheless, the surface roughness quality had similar pattern of very minimal variations even for speeds of 140 and $200 \mathrm{~m} / \mathrm{min}$.

\subsection{Effect of Cutting Time and Wear on Cutting Forces}

The progression of the three cutting forces as a function of cutting time and wear are depicted in Fig.8 and Fig.9.

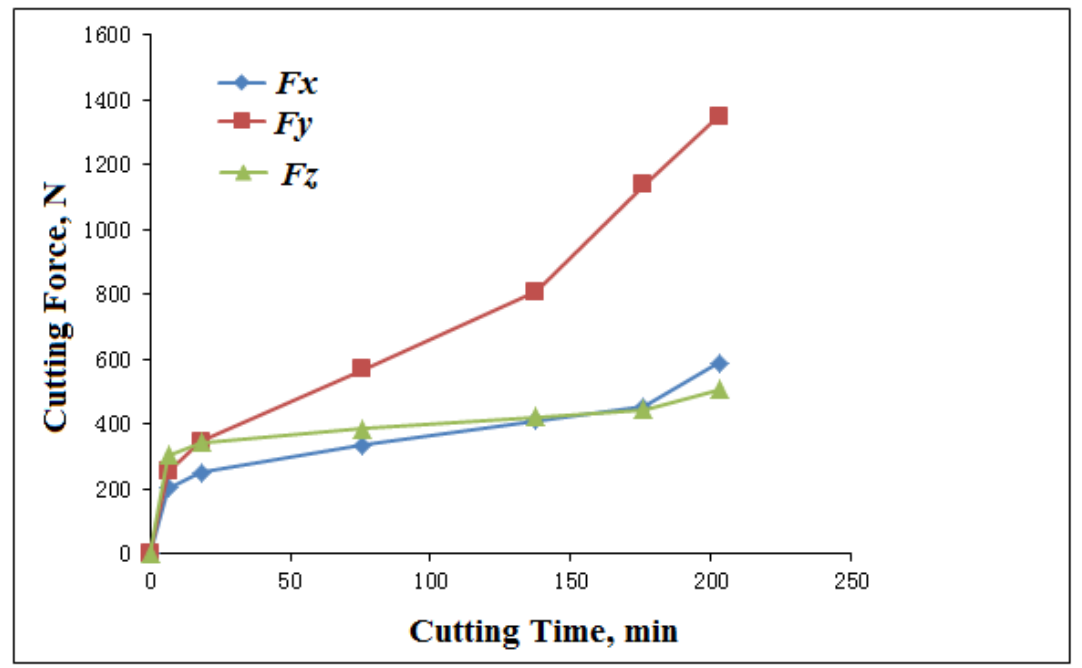

Fig.8: Effect of Cutting Time on Cutting Force at $V c=105 \mathrm{~m} / \mathrm{min} ; f_{n}=0.15 \mathrm{~m} / \mathrm{rev}$ 


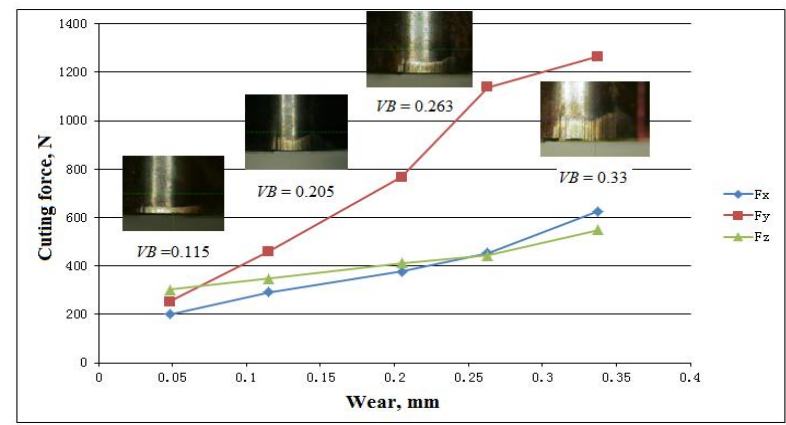

Fig.9: Influence of Wear on Cutting Force at $V_{c}=105 \mathrm{~m} / \mathrm{min} ; f_{n}=0.15 \mathrm{~m} / \mathrm{rev}$

The cutting force components increased with the evolution of cutting time. This was as a result of wear progression on flank surfaces of the tool. The workpiece- tool contact surface consequently increased with the friction forces producing higher cutting forces. The initial stage lasted 18 minutes and corresponded to $V B$ wear of $0.06 \mathrm{~mm}$, the cutting forces $\left(F_{x}, F_{y}\right.$ and $\left.F_{z}\right)$ noted were $249.51,344.51$ and $341.55 \mathrm{~N}$ respectively. The next phase ranged from $18 \mathrm{~min}$ to $138 \mathrm{~min}$ of cutting where the flank wear $V B$ measuredincreased from 0.06 to $0.231 \mathrm{~mm}$ resulting in an increase in the cutting forces $\left(F_{x}, F_{y}\right.$ and $\left.F_{z}\right)$ of respectively $39.32 \%, 57.34$ and 19.04\%. A steady increase during this phase was noted and was not as sharp as in the first stage. The last phase was described by a considerably quick wear of $V B$ value passing from 0.232 to $0.314 \mathrm{~mm}$ during a period of 138 to 223 minutes of cutting. The maximum cutting force values were achieved at this phase with an increase of $60.06,72.76$ and $37.75 \%$ when compared to the cutting forces $\left(F_{x}, F_{y}\right.$ and $\left.F_{z}\right)$ at the beginning and end of cutting. Micrographics of the PCBN tool flank wear taken at different wear stages are presented in Fig.9.

\subsection{Mathematical models for Tool Life}

Outcomes attained from Fig.3 permits the establishment of tool life models according to least square analysis for the $V B=0.3 \mathrm{~mm}$ limit wear standards. The models were computed at the three feed rates namely 0.15 , 0.2 and $0.3 \mathrm{~mm} / \mathrm{rev}$ to establish the relationship and the changes at these different feed rates. Therefore, the cutting speed range used in this investigation of 105 to $200 \mathrm{~m} / \mathrm{min}$, tool life can be explained by the equations in Table 7 .

Table 7: Tool life Mathematical Models as a Function of Cutting speed for $f_{\mathrm{n}}=0.15,0.2,0.3 \mathrm{~mm} / \mathrm{rev}$ and

\begin{tabular}{lccc}
\multicolumn{3}{c}{$\boldsymbol{a}_{\boldsymbol{p}}=\mathbf{0 . 5} \mathbf{~ \mathbf { m }}$} \\
\hline $\boldsymbol{V}_{\boldsymbol{c}}, \mathbf{m} / \mathbf{m i n}$ & $\boldsymbol{f}_{\boldsymbol{n}}, \mathbf{m m} / \mathbf{r e v}$ & Mathematical Models & $\boldsymbol{R}^{2}$ \\
\hline 105 & 0.15 & $T_{c}=e^{5.221} V^{-2.232}$ & \\
140 & & & 0.999 \\
170 & & & \\
200 & 0.2 & $T_{c}=e^{7.554} V^{-5.223}$ & 0.934 \\
\hline 105 & & & \\
140 & & & \\
170 & & & \\
200 & 0.3 & $T_{c}=e^{8.108} V^{-6.608}$ & \\
\hline 105 & & & \\
140 & & & \\
170 & & & \\
200 & & & \\
\hline
\end{tabular}


These models show quantitative relationships between the cutting speed and Tool life at various feed rates. Determination of the PCBN tool life as the function of expected cutting speed is made possible and eventual optimization of cutting processes in combination with the appropriate cutting parameters are possible. The coefficients $R^{2}$ determinedof the recommended models are close to unit especially at $f_{n}=0.15$, giving a decent correlation with the experimental outcomes. The coefficients $R^{2}$ varied from 0.934 to 0.999 in the cases above with highest at $f_{n}=0.15 \mathrm{~mm} / \mathrm{rev}$. Consequently, the established models can assist in the construction of Taylor straight line drawn on a bi-logarithmic scale in Fig.10 for the wear criteria $[V B]=0.3 \mathrm{~mm}$.

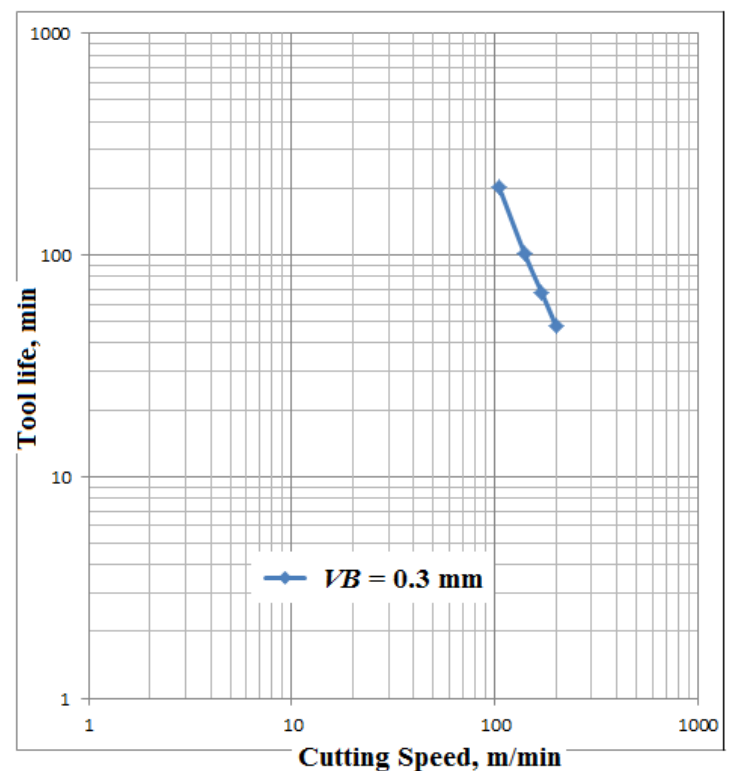

Fig.10: Effect of Cutting Speed on Tool Life Using Taylor Straight Lines at $V_{c}=105 \mathrm{~m} / \mathrm{min} ; f_{n}=0.15 \mathrm{~m} / \mathrm{rev}$;

$$
a_{p}=0.5 \mathrm{~mm}
$$

The line allows us determine economically the PCBN tool life when machining AISI 4140 steel hardened to $62 \mathrm{HRC}$, at any designated cutting speed ranging from 105 to $200 \mathrm{~m} / \mathrm{min}$. These models to a certain extent confirm that experimental results can be successfully used to develop models to aid effectively implementing a cutting process. To this effect the mathematical models were extended in the next section to include surface roughness as it plays a key role in finish machining.

\subsection{Surface Roughness Mathematical Models}

To appreciate the interaction between tool wear and workpiece roughness, it is prudent to propose a relation linking Roughness $\left(R_{a}\right)$ to wear $(V B)$. Even though $V B$ and $R_{a}$ are correlated to different parts, it is acknowledged that each one jointly influences the other and must conform to an independent relationship. Data scrutiny from the roughness-wear ( $V B)$ curves (Fig.8-9 allowed the development of general mathematical model in the equation:

$R_{a}=K \exp [\alpha(V B)]$

The numerical values of the constants $K$ and $\alpha$ are presented in Table 8 . The method suggests the possibility of regulating $V B$ making use of values of roughness measured from the workpiece and simultaneously calculating the remaining tool lifetime. In this way difficult tool data behavior obtained using constants $K$ and $\alpha$ turns into simpler data as summarized in the Table 8 by models of roughness as the function of wear in the given cutting conditions. 
Table 8: Roughness Mathematical Models as the Function of Wear $V B$ for $f_{\mathrm{n}}=0.15 \mathrm{~mm} / \mathrm{rev}$ and $a_{p}=0.5$

mm

$\begin{array}{cc}\text { Cutting Material } & \boldsymbol{V} \boldsymbol{c}, \mathbf{m} / \mathbf{m i n} \\ \text { PCBN } & 105 \\ \text { CNGA120408S01030AWH } & 140 \\ & 170 \\ & 200\end{array}$

$\begin{array}{cc}\text { Mathematical Models } & \boldsymbol{R}^{2} \\ R_{a}=0.554 \mathrm{e}^{0.167 V B} & 0.915 \\ R_{a}=0.334 \mathrm{e}^{5.272 V B} & 0.967 \\ R_{a}=0.384 \mathrm{e}^{2.006 V B} & 0.970 \\ R_{a}=0.576 \mathrm{e}^{1.395 V B} & 0.858\end{array}$

The recommended models can be utilized to estimate roughness $\left(R_{a}\right)$ as a function of wear $V B$ orthe other way around. The coefficients $R^{2}$ varied from 0.858 to 0.97 in the cases above with highest at $V_{c}=170$.

\section{CONCLUSIONS}

The practicality of hard turning using a PCBN tool for a specific hard turning application in most cases requires experimental evidence for it to gain industrial application. This research hoped to add empirical experimental data in this field to advance the use of PCBN cutting tools in industry and made the following conclusions.

- The present study outcomes indicated that PCBN tool suggests a good wear resistance regardless of the aggressiveness of the $42 \mathrm{CrMo} 4$ at $62 \mathrm{HRC}$. At $200 \mathrm{~m} / \mathrm{min}$, the machining system becomes uneven and results in significant sparks and vibrations just after a few minutes. This can be the highest cutting speed when low values of feed rates are used for PCBN tools utilization particularly when cutting hardened AISI 4140 steel. It was therefore recommended that to achieve improved tool life, slower cutting speeds $(105 \mathrm{~m} / \mathrm{min})$ should generally be selected in combination with suitable feed rates $(0.15,0.2 \mathrm{~mm} / \mathrm{rev})$.

- It was clear that tool lifewas sensitive to cutting speed variation. This could be due the presence of high temperatures produced around the tool nose by the cutting process supporting several wear mechanisms (abrasion and diffusion) and subsequently decreasing the cutting tool capacity. Abrasion wear was noted to be prominent and appeared by grooving on the flank surface as a result of tool particles being pulled out by the existing hard particles in the work piece material. At lower cutting speeds tool wear was mainly due to abrasion and due to diffusion, thermal softening and notching at higher cutting speeds.

- The coefficients $R^{2}$ determined for the quantitative relationships models between the cutting speed and Tool life at various feed ratesare close to unit especially at $f_{n}=0.15$, giving a decent correlation with the experimental outcomes. The coefficients $R^{2}$ varied from 0.934 to 0.999 with highest at $f_{n}=0.15 \mathrm{~mm} / \mathrm{rev}$. Consequently, the established models can assist in the construction of Taylor straight line drawn on a bi-logarithmic scale for the wear criteria $[V B]=0.3 \mathrm{~mm}$. The line allows us determine economically the PCBN tool life when machining AISI 4140 steel hardened to $62 \mathrm{HRC}$, at any designated cutting speed ranging from 105 to $200 \mathrm{~m} / \mathrm{min}$.

- Furthermore, a $V B$ and $R_{a}$ relationship was suggested in the form $R_{a}=K \exp [\alpha(\mathrm{VB})]$. The parameters $k$ and $\alpha$, are coefficients that varied respectively from 0.334 to 0.576 and 0.167 to 5.272. Results indicated that in general the surface roughness value decreases when cutting speed increases for all the feed rate values tested. At 140 and $170 \mathrm{~m} / \mathrm{min}$ the $R_{a}$ values are almost similar and the increase in cutting speed from 105 to 170 $\mathrm{m} /$ min reduces the surface roughness value due to the reduction in built up edge formation tendency. It was concluded that by utilizing a combination of lower level feed rate $(0.15 \mathrm{~mm} / \mathrm{rev})$ with higher level cutting speeds $(170 \mathrm{~m} / \mathrm{min}$ ) the surface roughness can be minimized. Even when the tool wear $V B$ reached $0.3 \mathrm{~mm}$, the majority of the recorded $R_{a}$ values did not exceed $1 \mu \mathrm{m}$ at the various speeds tested. This indicates that the PCBN tool can successfully be used for machining hard materials with satisfactory results comparable to 
grinding.

- The cutting forces increased with an increased PCBN tool wear. This was apparent when $V B$ was $0.314 \mathrm{~mm}$ after 223 minutes of cutting permitting 60.06, 72.76 and $37.75 \%$ increase of $F x, F y$, and $F z$ cutting force components respectively when machining at $105 \mathrm{~m} / \mathrm{min}$. The change in the cutting force due tool wear can be used to model this relationship in future studies as an additional variable to predict tool life

- The effect of feed rate on tool wear was quite significant when compared to proportionate changes in cutting speed. Therefore, by employing a combination of lower feed rate $(0.15 \mathrm{~mm} / \mathrm{rev})$ with a lower cutting speed $(105 \mathrm{~m} / \mathrm{min})$ a minimum tool wear was achieved.

\section{ACKNOWLEDGEMENTS}

The authors are grateful to The National High Technology Research and Development Program ("863"Program) of China (Grant No.2013AA041108) who supported this research.

\section{REFERENCES}

[1] Dawson, T. G., \& Kurfess, T. R., Modeling the Progression of Flank Wear on Uncoated and Ceramic-Coated PCBN Tools in Hard Turning, ASME Journal of Manufacturing Science and Engineering, 128(1), 2006, 104-109.

[2] Haron, C., Ginting, A., \& Arshad, H., Performance of alloyed uncoated and CVD-coated carbide tools in dry milling of titanium alloy Ti-6242S, Journal of material Processing Technology, 185, 2007,77-82.

[3] Tonshoff, H. K., Wobker, H. G., \& Brandt, D., Tool Wear and Surface Integrity in Hard Turning, Production Engineering, 3 (1), 1996,19-24.

[4] Choudhury, I. A., \& El-Baradie, M. A., Surface Roughness Prediction in the Turning of High Strength Steel by Factorial Design of Experiments, Journal of Materials Processing Technology, 67, 1997, 55-67.

[5] Azouzi, R., \& Guillot, M.. On-Line Optimization of the Turning Using an Inverse Process Neuro Controller Translation,ASME Journal of Manufacturing Science and Engineering, 120, 1998,101-107.

[6] Van, C. A., Luhervelt, T. H., Childs, I. S., Jawahir, F., \& Venuvinod, P. Present Situation \& Future Trends Modeling of Machining Operations Progress Report of the CIRP Working Group, Modelling of Machining Operations ,1998,pp. 587-626, Analysis of the CIRP.

[7] Krolczyk, G., Legutko, S., \& Gajek, M., Predicting the surface roughness in the dry machining of duplex stainless steel (DSS), Metalurgija, 52(2), 2013,259-262.

[8] Roy, S. ,Modelling of tool life, torque and thrust force in drilling: a neuro-fuzzy approach, International Journal of Simulation Modelling, DOI: 10.2507/IJSIMM09(2)2.149, 2, 2010,74-85.

[9] Yan, J., Murakami, Y., \& Davim, J. ,Tool Design, Tool Wear and Tool Life, In K. Cheng, Machining Dynamics: Fundamentals, Application and Practice (London: Springer 2009),133-138.

[10] Taylor, F. ,On the art of cutting metals, Transactions of the American Society of Mechanical Engineers, 28, 1907,pp. 31-58. Nova York.

[11] Mirkarimi, P. B., McCarty, K. F., \& Medlin, D. L. Review of advances in cubic boron nitride film synthesis. Materials Science \& Engineering R-Reports, 1997.

[12] Koning, W. e., Machining of hard materials. Annals of the CIRP, 1984, 417-427.

[13] Ding, X., Liew, W. Y., \& Liu, X. D., Evaluation of machining performance, Wear, 259, 2005,1225-1234.

[14] Liu, X. L., Li, Y. F., Yan, F. G., Wang, Y., Hu, J. S., \& Y. J. Wang, Study on precision grinding technique of PCD tool's cutting edge, Advances in Grinding and Abrasive Technology Xiii, 304-305, 2006, 186-190.

[15] ISO 3685, Tool-Life Testing with Single-Point Turning Tools, International Organisation for Standardization, (1993), 5-15.. 
[16] Chou, Y. ,Hard turning of M50 steel with different microstructures in continuous and intermittent cutting. Wear, 225, 2003,1388-1394

[17] Wang, J., Huang, C., \& Song, W., The effect of tool flank wear on the orthogonal cutting process and its practical implications, Journal of Materials Processing Technology, 142, 2003, 338-346.

[18] Huang, Y., Chou, Y., \& Liang, Y. ,CBN tool wear in hard turning: a survey on research progresses, International Journal of Advanced Manufacturing Technology, 35, 2007,443-453.

[19] Luo, S., Liao, Y., \& Tsai, Y., Wear characteristics in turning high hardness alloy steel by ceramic and CBN tools, Journal of material Processing Technology, 88,1999, 114-121.

[20] Zimmerman, M., Lahres, M., Viens, D., \& Loube, B., Investigation of the wear of cubic boron nitride cutting tools using Auger electron spectroscopy and Xray analysis by EPMA, Wear, 207, 1997, 241-249.

[21] Nabahani, F., Wear mechanisms of ultra-hard cutting tools materials, Journal of Materials Processing Technology, 115, 2001, 1388-1394.

[22] Reginaldo, T., Eu-Gene, N., \& Elbestawi, M., Tool wear when turning hardened AISI 4340 with coated PCBN tools using finishing cutting conditions, International Journal of Machine Tools and Manufacture, . 47, 2007,263-272.

[23] Liu, K., Li, X., Rahman, M., \& Liu, X., CBN tool wear in ductile cutting of tungsten carbide, Wear, 255, 2003,1344-1351. 